\title{
Community Life around Protected Areas in Cameroon: Conservation Story of Erat and the Resettlement Communities around the Korup National Park
}

\author{
Vukenkeng Andrew Wujung ${ }^{1}$, Cornelius Mbifung Lambi ${ }^{2}$, Dobdinga Cletus Fonchamnyo ${ }^{3}$, \\ Forbe Hodu Ngangnchi ${ }^{3, *}$, Muafueshiangha Ibrahim Menkeh ${ }^{4}$ \\ ${ }^{1}$ Department of Economics, Higher Institute of Commerce and Management (H.I.C.M), University of Bamenda, Cameroon \\ ${ }^{2}$ Department of Geography, University of Buea, Cameroon \\ ${ }^{3}$ Department of Economics, University of Bamenda, Bambili, Cameroon \\ ${ }^{4}$ Department of Finance, ECOM Trading, Nigeria
}

Copyright $\bigcirc 2018$ by authors, all rights reserved. Authors agree that this article remains permanently open access under the terms of the Creative Commons Attribution License 4.0 International License

\begin{abstract}
Current trend in the use or misuse of environmental resources raises strong sustainability issues and the need for preservation. But, should the environment be preserved at the expense of mankind? If the term 'sustainability' means the total subjection of the present generation to hardship and misery in favour of the wild (nature), then, 'sustainability' is not sustainable. This paper investigates into the quality of life of the Erat and the Resettlement community, formerly known as Ikondo Ikondo I of the South West Region of Cameroon using survey and retrospective designs. In reporting the untold conservation story of the two communities around the Korup National Park (KNP), primary data was collected from 180 participants using 5 point Likert scale questionnaire, and analyzed using the Taylor Linearized Standard Error Correction Technique. The result supports the hypothesis that wild nature is more 'valuable' than humans around the KNP as the population continues to be deliberately or otherwise subjected to hardship and misery. With an overall significant result tested using the Fisher's ratio, and while calling on the authorities to adopt measures that reduce poverty and provide social services and justice, the paper strongly advocates for a drastic shift from fortress to man-centred conservation. It is completely unacceptable that in the $21^{\text {st }}$ Century in Africa, man should be sacrificed for wild nature, no matter what, as he can conveniently live with nature. To achieve this global goal, conservation authorities should report the real impact of their activities.
\end{abstract}

Keywords Community Livelihood, Environmental Conservation, Protected Areas, Sustainability

\section{Introduction}

Environmental conservation in many parts of Africa has for a long time been a centralized matter in which resource management was dominated by the application of the fortress conservation model which posits a sharp divide between people's livelihoods and conservation [1]. Over the decades, there has been theoretical shift in the underlying conservation philosophy though only in principle with the view to getting governments to legitimize conservation initiatives. Cases of conservation practices can be likened to crime against humanity such as community re-location with no compensation. Future success in wildlife conservation depends on the current attitude towards our fellow humans [2]. Conservationists often hide the darker part of conservation history as millions of people are displaced worldwide and the livelihood source of community members criminalized [3].

The theory and practice of conservation today is seen to be deeply rooted in the concept of sustainability, yet, report suggests that Africa had a long history of preservation for cultural purposes [4]. If sustainability means that the current generation of poor must endure spartan conditions so that the next generation will have a better standard of living, then it lacks inter-generational justice [5]. Conservation can better be conceptualized on the basis of sustainability, as interdependent ecological, economic, social, cultural and good governance concerns [6]. In order to better understand the development challenges facing forest communities, it is important to understand the past economic and social history that gave rise to their present state of affairs [7]. Communities that have traditionally seen their lives and livelihoods supported by wild nature cannot develop without that natural consideration.

The fundamental causes of the contemporary environmental crisis of which climate change is the most serious lie not in an ineffective management of the earth's resources but in the logic of capitalism [8]. Successful conservation must adopt a social approach which reflects 
the natural history of Africa [9]. The conservation success of Europe and America cannot be directly compared to that of Africa because of historical differences. The decline in conservation area in Rwanda is due to perverse government policies, population pressure, and inadequate capabilities of forest institutions to enforce the rule of law [10]. Evidence from many parts of Africa suggest that governments are quick to create parks which evidently subject the population to hardship, but fail to follow up future programme development to enhance the park [11]. It is a hard truth that little implementation and enabling environments have been created to make protected areas in Cameron sustainable [12].

A conservation strategy that does not ensure the flow of direct and sustainable benefits to the local communities and the provision of meaningful and sustainable alternative employment opportunities cannot be relied upon in this era. Conservation approaches should place more emphasis on the human dimension [13]. One failure of the western style to wildlife conservation is the fact that they see the local population as enemies of wildlife conservation [3]. In many communities around protected areas, pressure continues to mount on the fragile resources being protected. A new form of democracy characterized by pre-defined conclusions that are technically imposed on the community is seen to exist in the process of creating many of the protected areas in Cameroon. The communities are lured to participate in decision making but their points of view are never seriously integrated within the overall conservation strategy. There is a need to create an enabling environment without violence or intimidation around protected area communities for success [12]. While the legislation allows for community participation in forest governance, no guiding framework exists to that effect [14]. Therefore, local people are constrained as the legislations do not match the reality and practice on the ground.

While the reality of conservation may vary from community-to-community, there appears to be many untold conservation experiences around the world. If the true story about how people feel around conservation sites is told, the funders who are predominantly from the north, would have a rethink about continuing the financial support mechanism. Though relocating an entire community for the sake of preserving wild nature may scientifically be justifiable, the conservationists are expected to review and consider the social implications of such displacements. One way of enhancing conservation is to look at how wildlife can be used sustainably, rather than prohibiting its use since for centuries, forest communities have relied on them for their survival [15].

Traditionally, a majority of areas requiring some forms of protection are found in the rural and marginal areas of most society. By implications, life around these areas is usually hard, characterized by extreme poverty with a general lack of social services and facilities to permit a decent living [11]. Conservation interventions that are supposed to reduce the level of hardship are seen to aggravate it within these rural vicinities. Despite the rapid paradigm shift from nature for itself through nature for man, to nature with man [16], man is clearly seen to be disregarded around the KNP in the South West Region of Cameroon. After 20 years of re-location for the sake of wild nature, the community of Ikondo Ikondo I is still awaiting the long standing promised conservation support amidst a fast eroding cultural identity. The story is not much different from the Erat community, though not re-located. Conservation agencies do not document and report the negative economic and social impact on the population [17]. Therefore, we ask the following questions: was wild nature created for man or man for wild nature? Is it a crime to be born in areas endowed with wild nature? On the basis of the above questions, this paper investigates into the determinants of the quality of life in the Erat and the Resettlement (Ikondo Ikondo I) communities of the Korup National Park (KNP) of Cameroon.

\section{Theoretical and Empirical Consideration}

Though the Environmental Kuznets Curve provides some compelling rational for conservation [18], the current conservation practices can be seen as a new evidence for the structuralist-dependency revolution. The countries of the north continue to ensure that a wide gap exists with those of the south in terms of development. Based on the foundation laid in the 1950s by the Economic Commission for Latin America and the Caribbean [19] and formalized by [20], the nations of the south would remain under-developed if the structure of the relationship is unchecked. The advanced countries of the world are either contributing directly or indirectly to the under-development of the third world economies through faulty advices or deliberate actions and inactions [21].

Today, the philosophy though coming from a different angle is basically the same. Conservation and funding agencies mostly from the North continue to advice for the resettlement, relocation and restriction of community life in favour of wild nature, though with limited recorded African success. As [22] reports, resettlement strategies have serious consequences on the life chances and cultural heritage of both enclaved and support zone communities. There is every reason to conclude that international conservation agencies have made life harder for the average community member around protected area, much like [23] concluded with the actions of the World Bank and the International Monetary Fund. The renewed interest in forest conservation is coming only when over $80 \%$ of the mature trees in third world countries have been harvested by countries and companies of the north. With independence, the logging industry in Cameroon was partly nationalised and partly taken over by private 
companies, often European [24]. This led to several decades of unsustainable logging, blighted by elite capture and corruption. Governments have been advised to restrict locals from cutting trees but grant exploitation permits to foreigners to exploit over time [25].

African and third world countries in 1990 gave back £2.4 billion in debt repayments to the United Kingdom more than they received in new loans, investment, export credit and aid from her government and charities [26]. Yet, western media reported the less charitable donations than the interest repayment. In post development literature, [27] and [28] advocated that the rich cannot lift the poor out of poverty. The emphasis was on the fact that local communities need to address their own problems, using their own ideas. Thus, implementing conservation from the present 'foreign context' is not sustainable within the African environment. Local communities could be empowered to create their own development ideas. The modernization of the world economy through science and innovation led to the destruction of some African cultural values that were development focused, citing the fact that Africans used herbs to cure [9]. Thus, empowering Africans to preach conservation themselves from the perspective of preserving the curative value of the forest and the environment could be a new indigenous approach. This means that the African equation would never be balanced if its traditional and cultural values are not well integrated into the conservation-development agenda. The African renaissance theory, unlike its predecessors, advocates for local solutions, pluralism, community-based solutions and reliance on local resources [9].

The development of the advanced countries was partially due to the exploitation and use of environmental and other resources of the less developed world [7]. Today, they encourage less economically developed countries leaders to follow their footpath to development. Yet, they are being prohibited from using those same natural resources they used. According to [29] as cited by [18], the early stage of development must be characterized by some level of environmental decay.

Though these dependency models provide limited practical alternatives to replace overseas reliance and assistance, $[20]$ noted that dependency did bring some level of development in the south in the form of higher gross domestic product and industrialization. In the short-term, the poorest of the poor may continue to struggle to meet their basic needs if development is awaited to come from within the local community. Most of the dependency theories are eclectic in nature, focusing on external dependence and neglecting domestic struggles, while obscuring an analysis of imperialism [30].

Policy distortions, market failures, corollary failure of underinvesting in human resources, and the lack of employment alternatives were identified as the root causes of environmental degradation and natural resource depletion [5]. The findings revealed that a good policy reform should be able to eliminate or at least reduce policy distortions that favour environmental unsound practices, correct or mitigate market failures, invest in human resources that promote local industries, and build technical capacities. The environment is vital to the human race because despite man's dominance on earth, he still depend on the environment for survival [31]. An environmental approach to conservation implies that each broad natural region should be regarded as an organic whole and developed to provide an optimum habitat for man [31]. The forest in the future must not be regarded just as a source of wood and forage, but as part of the living space for all the people both in the local and urban economy. There is a need in the human environment for wild nature, untouched or little modified by man's activities, whether for economic or aesthetic reasons [31]. The value of saving wild things as a sort of medical insurance for man cannot be over emphasized.

The history of environmental concern throughout the world with inspiration from the work of Rodrick Nash was modeled by [32]. In the model, the pre-ethical past was dominated by man's self that resulted to environmental damage. In what he termed the ethical past, the families, tribes, nations, and humankind continue to be the focus of the world with a complete neglect on the environment. The model finally reveals that for a better world, the international community must focus more on the environment including its plants and animals. It was strongly argued that a neglect of the environment is the neglect of the humankind because everything the human race depends on comes from the environment [32].

A double risk exists within the context of development-conservation initiatives in the South West Region of Cameroon and particularly with the eminent expansion of the Cameroon Development Corporation (CDC) plantations [14]. While the communities fear for the loss of their local livelihoods to the industrial giant, there is further risk of the disappearance of the rich biodiversity of the area. As pressure increases for more land to meet basic livelihoods of the local people, a process for negotiating compromises between different stakeholders is needed to ensure a flow of sustained benefits to all parties.

The Pygmies populations in the South Region of Cameroon have for the most part, been marginalised in the management of resources in their natural environment [33]. The forest which today is dedicated to achieving objectives that do not fit the views of the population constitutes the only place where they feel in harmony with nature through respect of their traditions. The conservation of the forest means the loss of forest myths and culture, and the loss of the idea that freedom and permanence are elements fundamental to existence, if establishing protected areas becomes synonymous with restricting this freedom. Thus, the work called for the provision of a special right to indigenous population to make use of the forest at least for subsistence and cultural purposes. 
Though Kupe Muanenguba Division is endowed with eco-tourism potentials, the resources are under-developed while others remain unknown to the authorities [34]. The authors recommended for the involvement of the indigenous people in the protection and conservation of the natural resources for touristic purposes. However, there certainly exist some missing links as [35] reported that the local populations are being systematically involved in conservation and natural resource management activities across the territory.

The populations of the South West Region of Cameroon are at the mercy of large-scale agriculture and conservation initiatives. Rural communities across Southwest Cameroon are experiencing a range of political conflicts resulting from large-scale land acquisition in which commercial interests are threatening local land-use practices and access to land [36]. The study showed that the struggle to maintain or redefine local livelihoods generates tension between inward competition for and outward contestation of claims to land. Therefore, reducing the influence of political elites in decisions making relating to land use can be of good interest to the population. Including all community stakeholders in land use management and the development of buffer zones around the Mount Cameroon Project site will help reduce conflict and enhance conservation efforts [37] and [38].

Protected areas are more important for science and culture than to human beings [39]. They observed that protected areas play a critical role in conservation of biodiversity, maintaining genetic resources, protecting important ecosystem functions and helping to protect many fragile human communities and cultural landscapes. In Cameroon, more concerted action among all stakeholders is needed in order to protect the environment whilst improving local livelihoods [40].

Interestingly, cocoa farms in the Mount Cameroon region generate more significant benefits for biodiversity conservation and local livelihoods than commercial plantations [41]. This implies that it is possible for cocoa farms to co-exist around protected areas though they warned that such co-existence mounts pressure on forest reserves, while the commercialization of cocoa plants endangers the environment.

In Cameroon, employment opportunities in surrounding villages to protected areas are rare and people rely on agriculture and the collection of Non-Timber Forest Products (NTFPs) for food and income [42]. While observing that areas of heavy human activity coincide spatially with great ape nest sites, they raised concern about the potential impact of human activities on great ape survival. They however called for the sustainable harvesting and marketing of NTFPs and the introduction of alternative livelihood opportunities to ensure the success of protected areas. In similar vein, [43] and [44] recommended that for the protected areas to survive, conservation approaches must be both culturally acceptable, and financially and ecologically sustainable.

A development activity in the form of artisanal mining greatly threatens conservation activities around two parks in the East Region of Cameroon, namely, the Nki National Park and Ngoyla Wildlife Reserve [25]. According to the findings, over 60 hectares of land was damaged by artisanal mining in the form of boreholes, temporary camps and road development. With rising population characterized by poverty around these nature reserves, there is every reason to suggest that such protected areas cannot survive. With the technical support of the World Wildlife Fund for Nature, it was recommended that the government should ensure the development of impact assessment before granting development or mining permits around protected areas. However, it is paramount to question whether the government is out to conserve or develop the local communities. The same government that created the parks that prohibited indigenes from undertaking any form of activity within it, granted mining permits to non-indigenes and foreign companies to exploit it. With high social injustice especially to the local population who are extremely poor, the park has no chance of survival.

Over $99.5 \%$ of the literature reviewed in this work made use of descriptive methodology in analyzing the information gathered. In this paper, we adopt a quantitative technique in analyzing the data collected, being the source of distinction. We have made significant attempt to quantify and measure all the variables in this study. The theoretical underpinning of this study strongly suggests the element of 'misleading' by the countries of the north to their counterparts of the south.

\section{Methodological Issues}

The KNP is a reserve created in the 1980s by the government of Cameroon in the South West Region by improving the status of the former Korup Forest Reserve established by the British Administration in the 1930s. It covers a total surface area of about 126,000 hectares, and it is close to the border with Nigeria. Being a predominantly forest community, the people's main occupation is hunting and farming, with 5 villages located inside the park [45]. While the rich nature of the soil attracted the plantation giant, PAMOL PLC since 1952, the rich nature of the forest has also been of interest to forestry and wildlife authorities, placing the communities at the cross road. This research adopts a retrospective and survey design to investigate into the challenges of livelihoods in the face of the limited land available to indigenous people due to non-indigenous conservation and development interventions. With the help of 180 questionnaires, focused group discussions and stakeholder interviews in two of the villages close to the park, the study adopts the Taylor Linearized Standard Error Correction Technique given its 
BLUE properties [46] to analyse the data. Regressing community wellbeing against the major determinants, the linear mathematical model specified as shown below has been logged so as to make a highly skewed variable more approximately normal [47].

$\log \mathrm{QL}_{\mathrm{i}}=\mathrm{a}_{0}+\mathrm{a}_{1} \log \mathrm{CL}_{\mathrm{i}}+\mathrm{a}_{2} \log O P E \mathrm{~N}_{\mathrm{i}}+\mathrm{a}_{3} \log \mathrm{AL}_{\mathrm{i}}+\mathrm{a}_{4} \log \mathrm{AC}_{\mathrm{i}}$ $+a_{5} \operatorname{logSS} \mathrm{i}_{\mathrm{i}}+\mathrm{a}_{6} \log \mathrm{Pov}_{\mathrm{i}}+\mathrm{a}_{7} \log \operatorname{DepRa}_{\mathrm{i}}+\mathrm{a}_{8} \log \mathrm{Dep}_{\mathrm{i}}+\mathrm{u}_{\mathrm{i}}$

Where, $\mathrm{QL}_{\mathrm{i}}$ equals the quality of life measured descriptively by satisfaction or happiness [48]. This measure reflects the ease by which people are able to satisfy their needs [60]. $\mathrm{CL}_{\mathrm{i}}$ measures the cultivable land in terms of the percentage of total community land developed for agricultural purpose; $O P E N_{i}$ is the ease of access to the community and market by road network. Access to market remains a growing problem for third world societies. $\mathrm{AL}_{\mathrm{i}}$ is the existence and use of alternative livelihoods provided by conservation authorities [49]. $\mathrm{AC}_{\mathrm{i}}$ is the variable that measures the degree of attachment to cultural values. $\mathrm{SS}_{\mathrm{i}}$ measures the availability of social services such as educational establishments, potable water system, electricity and telecommunication facilities. $\operatorname{Pov}_{i}$ is the level of poverty in the community estimated using the basic need approach and poverty line as a base. An individual is poor if his/her earning is below the poverty line of 1USD per day [50] and [51]. DepRa $a_{i}$ is the dependency ratio of the communities, measured as a ratio of total dependent to active basic needs providers [52]. Dep $\mathrm{p}_{\mathrm{i}}$ is deprivation measured as the extent to which villagers are restricted from having access to the basic resources of life in their environment [48]. The economic wellbeing of individuals is largely determined by their command over economic resources [53]. All the variables are measured and quantified with the help of the Likert scale, composed of a series of 5-6 Likert type items that are combined into a single composite score/variable [54] and [55].

Parameters estimated in this study are $\mathrm{a}_{1}-\mathrm{a}_{8}$, being coefficients of the variables. Based on the relevant literature, $a_{1}>0, a_{2}>0, a_{3}>0$ and $a_{5}>0$ while the rest are less than $0 . a_{0}$ is the constant term and $\mathrm{u}$ is the error term. In this case, the coefficients of the estimated parameters are interpreted as elasticities. The statistical significance of the variables, the overall model and reliability were tested with the help of the student t-statistics, the Fisher's ratio and the Cronbach's Alpha test respectively.

The Cronbach Alpha is an instrument that allows us to test the internal consistency or strength of a set of scale items. The test is constructed by correlating the scores for each item with the total score for each observation and comparing that with the variance of all individual items. The test value ranges from $0-1$, with the former showing no correlation and the latter showing high covariance. A minimum alpha coefficient of 0.65 is generally recommended [59].

\section{Presentation and Discussion of Results}

The results of the field survey conducted shows that the 180 questionnaires administered registered a retention rate of $100 \%$ given that it was administered by the authors directly, with $42 \%$ of the respondents being females and $58 \%$ males. The youngest respondent was 19 years old. On the average, the standard deviation of the responses was below $50 \%$, implying that individual views were convergent. It implies that the community members that were selected for this study had similar feelings/views in relation to the subject matter under investigation.

In testing for the validity of the various constructs used to measure or capture the concepts used in this study, we employed the Cronbach's Apha test with the results presented as follows:

Table 1. Results for Cronbach Alpha test

\begin{tabular}{|c|c|c|}
\hline Variables (Constructs) & $\begin{array}{c}\text { Cronbach Apha } \\
\text { coefficient }\end{array}$ & Remark \\
\hline CL (cultivable land) & 0.72 & Good \\
\hline $\begin{array}{c}\text { OPEN (Openness of the } \\
\text { community) }\end{array}$ & 0.91 & Excellent \\
\hline $\begin{array}{c}\text { AL (Alternative } \\
\text { livelihood) }\end{array}$ & 0.85 & Excellent \\
\hline $\begin{array}{c}\text { AC (Attachment to cultural } \\
\text { value) }\end{array}$ & 0.94 & Good \\
\hline $\begin{array}{c}\text { SS (Availability of Social } \\
\text { Services) }\end{array}$ & 0.79 & Excellent \\
\hline Pov (Poverty) & 0.86 & Good \\
\hline $\begin{array}{c}\text { DepRa (Dependency } \\
\text { Ratio) }\end{array}$ & 0.88 & \\
\hline Dep (Deprivation) & 0.99 & God \\
\hline
\end{tabular}

Source: Authors, 2018

According to the result, the multiple-question Likert scale surveys used for this study are reliable. This is because all the variables have coefficients of above 0.7 . This implies that the various constructs reliably measure the different concepts they were intended to [56]. With face validity that was supported by both literature and theory, we concluded that the various constructs were reliable.

The regression result is summarized below with t-values in parenthesis. * indicate $5 \%$ level of significance.

$$
\begin{aligned}
& \mathrm{QL}=2.71+0.14 \mathrm{CL}+0.12 \mathrm{OPEN}+0.08 \mathrm{AL}-0.22 \mathrm{AC}- \\
& 0.21 \mathrm{SS}-0.18 \mathrm{Pov}-0.06 \mathrm{DepRa} \neg-0.27 \mathrm{Dep} \\
& \begin{array}{llll}
(1.15) \quad(1.37) \quad(1.15) \quad(-2.97)^{*}
\end{array} \\
& (-2.08)^{*} \quad(-2.39)^{*} \quad(-0.69)^{*}
\end{aligned}
$$

The result shows that apart from the variables specified in this model, other variables do exist that together positively affect the quality of life of the population of Erat and the Resettlement community of the KNP since the constant term is positive $(+2.71)$. Such factors may include but not limited to tolerance, resilience, hard work and resolve to succeed despite all the conservation odds. Trade is another important factor because being a border 
community to Nigeria, advantage can be taken of exchange rates fluctuations to maximize economic outcome.

The percentage of land under cultivation is positively related to the quality of life. This was expected as farming is the main source of food and income for the population. Increasing the amount of farm land could significantly improve on their wellbeing. Unfortunately, restriction by conservationists, the growing PAMOL Plantation Plc., the development of small holder schemes by the Catholic Church and private individuals originating from out of the local community currently place the population at a cross-road. Sometimes, we are tempted to question why the industrial giant was allowed to destroy wild nature and establish, while the poor villager is not allowed. This situation invokes the issue of social injustice which helps to reinforce rural poverty.

The result also reveals that accessibility is positively related to the wellbeing of the population with a coefficient of 0.12 . This means that for every $1 \%$ effort to dis-enclave the area through opening of access roads, wellbeing improves by at least $0.12 \%$ point, ceteris paribus, similar to the findings of [21]. At the moment, the community especially Erat is not easily accessible by motorbikes even in the dry season. It can only be described as horrible that in this age of globalization, the park authorities have only opened foot tracks to link the population to Mundemba, the administrative headquarters of the Division. Reports suggest that the authorities are not willing to open motorable roads on two counts: (1) it will encourage timber exploitation and (2) it will disconnect the forest thereby making movement by wildlife difficult. Under these circumstances, it may be concluded that it is a crime to live beside a naturally endowed site.

The regression result also shows that alternative livelihood provided by the conservation authorities has a positive effect on the wellbeing of the population with coefficient of 0.08 . This is particularly important for the resettlement community who left their village (Ikondo Ikondo I) with no means of survival. The forest communities live a life that can be described as 'hand-to-mouth'. Without basic conservation support in the form of houses and other basic needs of life, the community cannot sustain itself, a finding consistent with [22].

The study suggests that the attachment to cultural values in the form of beliefs and worship are negatively affecting the population with a coefficient of -0.22 . This can be explained in terms of loss productive time due to traditional practices and beliefs. Every year, a total of at least 3 months are lost due to cultural practices such as the 'efeng festival', the 'nyampe' and the 'anyap' traditions, just to name a few. How do you produce much food to take care of your household if a significant amount of time is wasted on unproductive cultural practices? Though culture is not bad in itself, the level of practice should be consistent with the ability to meet other basic needs of life. It is not easy to displace forest people because of their high attachment to culture [57].

The near complete absence of social services in the communities such as potable water system, electricity, network availability for electronic communication, medical facility (for resettlement), just to mention these few are negatively affecting the wellbeing of the population. Findings suggest that almost $1 / 3$ of all the children that were re-located from their original homes died in the new camp basically due to lack of medical services which is a key social facility for the people. Life today is incomplete without electricity, without internet and without a good water system. The absence of these services/facilities cost wellbeing by about $2.1 \%$ point margin, which is statistically significant at $5 \%$. In the Erat community and Ikondo Ikondo I before resettlement, at least $85 \%$ of all those who were literate studied in neighbouring Nigerian schools and colleges. Though a medical centre exists in Erat, there is no resident Medical Officer with only a nurse on stand-by with limited or no resources for a population of close to 600 inhabitants. It may be interesting to remark that animals are given medication in the forest when no medical facility exist for fellow humans living side-by-side these animals in the 21st Century.

Poverty is one of the main variables responsible for the inability of the forest communities to maximize wellbeing. With a regression coefficient of -0.18 , an increase in poverty can only worsen the living conditions of the population. The average individual in the community lives on less than 1USD per day, with very low calorie intake as the traditional and frequently eaten mill is not nutritive. Being statistically significant, poverty cannot permit an individual to live a fulfilled life, with restricted access to basic environmental resources that are necessary to enhance wellbeing. Poverty manifests in several aspects of community life such as the inability to foot heath care bills, school fees, eat good food amongst others. Poverty is aggravated by the excessive drinking of cheap liquor from neighbouring Nigeria, which has made savings almost inexistent in the community. This is compounded by the absence of micro finance service schemes.

The increasing number of inhabitants under the care of a family head has a negative effect on the wellbeing of the population. With an average household size of about 15 persons under the care of a single family head, life can never be better. The more the population within a household, the greater the hardship endured by the family. In statistical terms, for every $1 \%$ increase in the dependent population, welfare degrades by at least $0.6 \%$ on the average.

The degree of deprivation is also observed to negatively affect the population. Deprivation in terms of access denial for the harvesting of NTFPs, access denial for hunting and caring for already developed farms within the park vicinity, restriction in terms of the nature of activities to undertake 
in the community, just to mention a few all negatively affect the wellbeing of the local communities investigated in this study. Given the various forms of restrictive practices, there is loss revenue from foregone timber exploitation, from harvesting of other forest products with a direct effect on welfare. According to the villagers, '...two of our brothers have been shot dead by conservation authorities in the forest and when the population rose, armies were ordered by the administration to crack down on us...'. Being statistically significant at $5 \%$, there is every reason for an arrangement that allows the villagers to harvest NTFPs at least from peripheral environment before the government permits foreign firms to exploit [25].

Given the coefficient of multiple determination (adjusted $\mathrm{r}^{2}=62 \%$ ) and an overall significance based on the Fisher-ratio $(\mathrm{F}=0.00)$, the result is said to be statistically significant and relevant for policy discussion.

\section{Summary of Findings, Recommendations and Conclusion}

From the study, the following findings can be recapitulated: The people of Erat and Ikondo Ikondo I communities, now referred to as "Resettlement Village" of the KNP are at a crisis crossroad, being constrained from one end by the large industrial plantation, PAMOL PLC, the small holder plantation of the Catholic Church and the KNP from the other end. These developments place a limit to settlement and farmland expansion, with dire consequences on welfare. With rapid birth rate and extremely high household density with over 15 persons on average per household, the communities are bound to face future conflict with both park and private development initiatives.

The Erat community is highly enclaved, with the near absence of access by road even in the dry season. With cultural practices that are counter-productive, the degree of poverty observed in the area is not surprising. This has a significantly negative effect on the general wellbeing of the population.

It was also observed that basic social facilities such as pipe borne water, electricity, medical centres, tele-communication facilities amongst others are almost inexistent in the communities visited, though Erat has a health centre with no medical officer on duty. The medical store was dusty by the time the field work was conducted with no one on seat to answer basic research questions. The sign post for the installation of a solar power system installed some 15 years ago was seen in Ikondo Ikondo I, with no sign of electricity coming soon as it was rusted already. Similarly, local houses at Erat village were wired with solar electrical cables with no solar system in place as the entire community was fed up with fake promises by conservation and administrative authorities [59].
On the basis of the above findings, the following policy issues are highlighted:

- Given the level of poverty around this protected area, the population should be allowed some degree of access into the periphery of the park to harvest basic NTFPs for livelihoods. It is also strongly recommended in this paper that a significant support be given to the population by the park authorities especially the displaced villagers through the introduction of varieties of income generation activities. By disenclaving the community, poverty level can be significantly reduced as products will be easily transported to the market. Trekking for 6 hours or more to the nearest market in Nigeria is not healthy for the population. Poverty can also be reduced by integrating the educated locals as permanent employees of the park and related services.

- While cultural festivities are encouraged, the elements of the culture that are counter-productive should be revisited for economic and social progress. The village development association could work with the traditional authorities to identify and modify unproductive cultural practices.

- The public authorities should engage the process of providing basic social services to the communities as a matter of urgency. Many lives were lost immediately after re-location because of the complete lack of social services. The participation of the private sector can be encouraged through some incentives by the state.

- While population increase is needed for industrial progress, the growth rate that is consistent with such progress must be maintained. The household density, which measures the degree of concentration of individuals within a household, must be reduced through proper education. The higher the population growth, the greater the risk of park sustainability in the long run.

In the absence of these measures, the limited environmental resource is at a greater future risk than we are currently experiencing. In this way, integrating local communities into the overall conservation agenda in a holistic approach will be beneficial to both interest groups. Conservation has traditionally been at logger-head with the community because the local population is often viewed as 'enemies to wildlife'. Though conservation and development objectives are always conflicting [58], they can co-exist if well developed. It is time to see the local population as a principal actor in conservation rather than enemies to it. It is time to reverse the trend where landlords in the name of 'charity organizations' continue to inflict irreversible pains on innocent poor villagers whose only crime is that their fathers and grand-fathers lived and worked in environmentally rich forest communities. 
According to [22], less than $30 \%$ of the master plan of the KNP has been implemented. Therefore, conservation authorities must sit up by avoiding false promises to the communities as short term incentives to conservation.

\section{REFERENCES}

[1] Mfune O. From Fortresses to Sustainable Development: The Changing Face of Environmental Conservation in Africa, the case of Zambia. PhD thesis, University of Glasgow; 2012

[2] Pellew R. People Come First. WWF UK News Quarterly, Winter Issue; 1993

[3] Duffy R. Nature Crime: How we are getting Conservation Wrong; 2010

[4] Maddox GH. Africa and Environmental History; Journal of Environmental History Number 4, issue 2, Pp162-167; 1999

[5] Panayotou T. Green Markets: The Economics of Sustainable Development. International Centre for Economic growth and the Harvard Institute for International Development, ISBN: 1-55815-244X; 1993

[6] Schroeder R. \& Schroeder K. Happy Environments: Bhutan, Interdependence and the West. Sustainability Volume 6, pp3521-3533; 2014

[7] Gunder AF. Thinking about Development: 'The Development of the Underdevelopment', Monthly Review, pp27-38; 1966

[8] Carton W. Nature and the Myth of a Sustainable Capitalism. On the Environmentalist Transformation of Capitalism and its Potential in Overcoming the Environmental Crisis. A Master Thesis, Aalborg University; 2009

[9] Matunhu JA. Critique of the Dependency and Modernization Theory in Africa: Critical Assessment. African Journal of History and Culture Vol. 3(5), Pp65-72; 2011

[10] Masozera MK. Socioeconomic Impact Analysis of the Conservation of the Nyungwe Forest Reserve, Rwanda. A Thesis Presented to the Graduate School of the University of Florida in Partial Fulfillment of the Requirements for the Degree of Master of Science; 2012

[11] Forbe, HN, Njimanted GF \& Lambi CM. Environmental Conservation in Cameroon: Poverty Reduction or Aggravation? Empirical Evidence from the South West Region of Cameroon. International Journal of Resources and Environmental Management, Vol. 1, No. 2, pp41-54; 2016

[12] Lambi CM, Kimengsi JN, Kometa CG, \& Tata ES. The Management and Challenges of Protected Areas and the Sustenance of Local Livelihoods in Cameroon. Environment and Natural Resource Research, Volume 2, No. 3, Canadian Center for Science and Education; 2012

[13] Muhumuza M. and Balkwill K. Factors Affecting the
Conservation of Biodiversity in National Parks: A Review of Case Studies in Africa. International Journal of Biodiversity, Volume 2013, ID 798101; 2013

[14] The Mount Cameroon Project Policy Briefing. Community Wildlife Management-Making Legislation Meets Reality. Policy Briefing Note No. 3; 2001

[15] WWF UK. Quarterly News, Winter 1993/94 Issue

[16] Mace GM. Whose conservation? American Association for the Advancement of Science Vol. 345, No. 6204, Insights Perspective Ecology, Pp 1558-1559; 2014

[17] Brazeau CAM. Accountability, conservation and community: Measuring the Local Economic Impact of Protected Areas. Thesis and Dissertation, Wilfrid Laurier University, Scholars Commons; 2017

[18] Yandle B, Maya V, \& Bhattarai M. The Environmental Kuznets Curve; A Primer; 2002

[19] Ateş H, Es M \& Bayraktar Y. Dependency Theory: Still an Appropriate Tool for Understanding the Political Economy of the Middle-East? İktisadive İdari Bilimler Dergisi, Cilt: 9 Eylül, Say1: 2, pp248-262; 2005

[20] Cardosso FH. \& Falleto E. Dependency and Development in Latin America, University of California Press; 1979

[21] Ferraro V. Dependency Theory: An Introduction, Mount Holyoke College South Hadley; 1996

[22] Oshuo EJ. The Socio Economic Implications of the 1996 Resettlement Enclave and Host Communities in the Cross River National Park, Owangwo Division. Journal of Applied Social Sciences, Volume 6, Number 1 \& 2; 2017

[23] Stiglitz JE. Making Globalization Work: The Roaring Nineties Globalization and Its Discontents; 2006

[24] Merlet M \& Fraticelli M. Protecting Forests, Improving Livelihoods: Comparing Community Forestry in Cameroon and Guatema. ISBN: 978-1-906607-62-3; 2016

[25] Sumelong E. Artisanal Mining Threatens Protected Area in the East Region of Cameroon. The Post News Paper No. 01807, Monday March 27 $7^{\text {th }}$, Pp. 9; 2017

[26] Uche LU. Some Reflections on the Dependency Theory. Africa Media Review Vol. 8, No. 2, African Council for Communication Education; 1994

[27] Escobar A. Imagining a Post-Development Era? Critical Thoughts, Development and Social Movement; 1992

[28] Ziai A. Exploring Post-development: Theory and Practice, Problems and Perspectives. Routledge, Taylor \& Francis Group e-Library; 2007

[29] Kuznets S. Long-term changes in the national income of the United States of America since 1870. Review of income and wealth, 2(1), 29-241; 1952

[30] Chilcote R.S. Dependency Theory: A Reassessment: A Critical Synthesis of the Literature. Latin American Perspectives Vol. 1, No. 1, pp4-29; 1974

[31] Keller EA. The Evolution of Ethics: Does Rocks have Rights? Environmental Geography. Second edition, Charles E. Merrill Publishing Co.; 1978 
[32] Dasmann RF. Environmental Conservation, $2^{\text {nd }}$ Ed., John Wiley and Sons, Inc., New York; 1968

[33] Ndameu B. Protected Areas and Indigenous Peoples: The Paradox of Conservation and Survival of the Baka in Moloundou Region (South-east Cameroon) Case 7, Cameroon - Boumba Bek, Pp 215-241; 2001

[34] Balgah SN and Nfor F. An Assessment of Ecotourism Potentials in Kupe Muanenguba Division, South West Region, Cameroon. International Journal of English, Literature and Social Science (IJELS), Vol.2, Issue 3, 2017

[35] Nelson J. Indigenous Peoples' Participation in Mapping of Traditional Forest Resources for Sustainable Livelihoods and Great Ape Conservation. Report to the United Nations Environment Programme (UNEP); 2008

[36] Ndi FA. and Batterbury S. Land Grabbing and the Axis of Political Conflicts: Insights from Southwest Cameroon, in: Africa Spectrum, 52, 1, 33-63. URN: http://nbn-resolving.org/urn:nbn:de:gbv:18-4-10203; 2017

[37] Vukenkeng AW \& Badjo NMA. The Impact of Income Generating Activities on the Environment. The Experience of some Five Neighbouring Villages of Mt. Cameroon. Journal of Resources Development, Vol. 27, Pg 17-24; 2016

[38] Djeukam, RN., Ntolo, M., Dinga, N., Tedjiozem, R., Talla, M., \& Njike, H. The Wildlife Law as a tool for Protecting Threatened Species in Cameroon. Ministry of Forestry and Wildlife, MINFOF, Yaoundé, Cameroon, 2012.

[39] Dudley N and Phillips A. Forests and Protected Areas. Guidance on the use of the IUCN Protected Area Management Categories. World Commission on Protected Areas (WCPA) and Best Practice Protected Area Guidelines Series No. 12; 2006

[40] Dinsi SC \& Eyebe SA. Great Ape Conservation in Cameroon: Mapping Institutions and Policies. Poverty and Conservation Learning Group, PCLG Research Report; 2006

[41] Laird SA, GL Awung \& RJ Lysinge. Cocoa Farms in the Mount Cameroon Region: Biological and Cultural Diversity in Local Livelihood. Springer Science Business Media B.V; 2007

[42] Etiendem DN, Nikki T, Hens L \& Pereboom Z. Impact of Human Activities on Cross River Gorilla (Gorilla gorilla diehli) Habitats in the Mawambi Hills, Southwest Cameroon. Endangered Species research Journal Vol. 20, Pp.167-179; 2013

[43] AJEME Self Help Group. Forest Communities and their Traditional Way of Life. The Case of Nguti Council Forest, South West Region of Cameroon. Project Report Financed by the Rainforest Foundation, UK; 2016

[44] Lamarque F, Anderson J., Fergusson R., Lagrange M., Osei-Owusu Y. and Bakker L. Human Wildlife Conflict in Africa: Causes, Consequences and Management Strategies.
FAO Forestry Paper Number 157; 2009

[45] Mbile PN. Management and Business Plan of the Korup National Park. Produced by CLIM-DEV-CAM; n.d

[46] Njimanted GF, Molem CS \& Achuo ED. Petroleum Products Price Fluctuations and Economic Growth in Cameroon. Growth Vol. 2, No. 2, pp30-40; 2015

[47] Benoit K. Linear Regression Models with Logarithmic Transformations. Methodology Institute, London School of Economics; 2011

[48] Dajana C, Tomislav Ć. Macro and Micro Aspects of Standard of Living and Quality of Life in a Small Transition Economy: The Case of Croatia. Working Paper Series No. 10-02, Faculty of Economics and Business, University of Zegreb; 2010

[49] International Trade Centre. Market Access Barriers: A Growing Issue for Developing Country Exporters? Issue Number 2; 2003

[50] Deaton A. Measuring Poverty in a Growing World. The Review of Economics and Statistics Volume LXXXVII, Number 1; 2005

[51] Instituto Nacional De Estadística. Measuring welfare; n.d.

[52] OECD. Age-Dependency Ratios: Definition and Measurement. Society at a Glance: Social Indicators-ISBN 92-64-02818-8; 2007

[53] Australian Bureau of Statistics. Household Income and Income Distribution; 2007

[54] Boone HN and Boone DA. Analyzing Likert Data. Journal of Extension Vol. 50, No.2; 2012

[55] Clason DL, and Dormody TJ. Analyzing Data Measured by Individual Likert-Type Items. Journal of Agricultural Education, Volume 35, No. 4; n.d.

[56] Tavako M and Reg D. Making sense of Cronbach's alpha. International Journal of Medical Education, volume 2, pg53-55 ISSN. 2042-6372; 2011

[57] Mpeh LT. Management of Forest Resources in the Korup National Park and the Bayang Mbo Sanctuary: A Human Right Perspective. African Journal of Social Sciences, Vol. 6, No.4; 2015

[58] Moto TMN. Community Conflict over Forest resources in the Southern Bakundu Forest Reserve, South West Region of Cameroon. International Journal of Resource and Environmental management, vol. 1, No. 1; 2016

[59] Gaforth C. Using and Interpreting Cronbach's Alpha. University of Virginia Library, 2015

European Foundation of living and working conditions (2007): Quality of Life in Croatia: Key Findings From National Research 